\title{
The Role of the Restaurant Sector in Promoting the Local Cuisine. The Case of Shkodra City
}

\author{
Romina Dhora, PhD (c) \\ University of Shkodra "Luigj Gurakuqi" \\ Dr Brikenë Dionizi \\ University of Shkodra "Luigj Gurakuqi"
}

Doi:10.5901/ajis.2014.v3n2p327

\begin{abstract}
One of the key components in the development of gastronomic tourism is the promotion of the local cuisine. The use of the local food by restaurants is a significant way of promoting the local cuisine as well as establishing collaborative relationships with the local producers. This alternative leads also in the increase of the local production and in the improvement of the returns of their investment. Restaurants which use the local cuisine in their menus face an opportunity of marketing their menus, potentially leading to ongoing purchase of the local food. Shkodra as a touristic destination holds great potentials in the development of gastronomic tourism. This destination owns a large heritage in cuisine, in local food production, techniques of productions and a variety of recourses. The purpose of this paper is to analyze the willingness and ability of the restaurant managers to use and promote the local cuisine in their menus. Research was carried out through a questionnaire delivered in 39 restaurants registered in Shkodra region and in-depth interviews with chef restaurants and managers. The questionnaire was divided in two parts. The first part investigated the extent to which managers and chefs of restaurants assess the role of local food in their business. The second part of the questionnaire evaluates how much do local food affect tourists in the choice of a destination, according to managers and chefs restaurants. This was done to explore the possibility that Shkodra destination has to develop gastronomic tourism and the effect that tourism has in their business. The conclusion of this study was that the restaurants are integrating in their menus the local food because there is an increase in the demand for local produce. This study indicate that restaurants need to cause much more attention to this relationship as a better way to raise authentic experiences.
\end{abstract}

Keywords: restaurants, local cuisine, authenticity, tourism quality management

\section{Introduction}

One of the most essential elements in the relationship between food, tourism and local development is the sector of restaurants. The use of local food in restaurants increases the level of local production. Meanwhile, the marking of restaurants' menus based on local food is a good alternative of menus and restaurant's marketing (Henchion and McIntyre, 2000). In addition, the use of local food on a restaurant business affects in the perceived growth of the level of authenticity of the restaurant's experience that extends more in the width of destination (Fox 2007). Restaurants have an essential impact in tourism development offering to tourists not just the food but also the experience. In fact restaurants are not created just for food purpose because food industry has a supporting role and is an important part of tourism industry.

Food is determined as one of the motivators of the trip and as a factor that influence also in the choice of restaurants from tourists ((Hall dhe Michell 2006). Tourists consider as 'an attraction' a place that let them show, be part of and be more sensitive. So a 'touristic attraction' is a physic development that offers to tourists the possibility to gain experience through coordination (Gunn, C.,1979)

In order to increase the level of investment return to farmers, rural areas are in search of developing direct relationships between local producers and restaurants. On the other hand, cuisine chiefs and restaurants managers seek to establish a cooperative relation with local producers hoping favorable prices. The benefit is mutual and can be seen in both aspects (Chang et al., 2011).

The reasons that lead restaurant managers to local producers:

- Most restaurants have an owner that enables purchase everywhere that he wants 
- Restaurant menu changes constantly and the purchase of seasonal products is an easier alternative

- The demand of restaurants is from a lower level than other institutions and the possibility of completion of this request is higher.

- Customers are available to pay more for a menu unit that uses qualitative products grown bio (Scanlan and Associates, Huber, G and Karp, R 2000 )

- Advantages of direct sales at restaurants for local producers:

- Market security. If a cooperative relation with a restaurant is placed, in this relationship are determined also the price and the amount of requested product.

- Personal contact with owners, managers or cuisine chiefs offers flexibility in product growth and also in information collection from clients regarding to product quality.

- Name or brand recognition. If restaurants emphasize the name of local producers on their menus then the level of name or brand recognition increases offering new opportunities (Gibson 1995 pg 35).

Restaurants and food experiences are an important element for tourists and their tourist experiences. The purpose of their study is to understand the role that this sector has in the level of attractiveness of a tourist destination. Local foods or foods that are produced based on local tradition can create a competitive advantage for restaurants that serve them, impacting in differentiation of destination. Furthermore another positive effect is the impact that restaurants have in the improvement of products produced based on local tradition or restaurant experiences that tourists gain.

Restaurants change in the way how they are positioned in market. Most restaurants believe on service quality and its impact in customer satisfaction. That's why they choose a specialized and trained staff in terms of qualitative service. Many restaurants emphasize the local nature of food using different ways mentioning the emphasis of local dishes on menu or the presentation of different appetizers. But few of them use the narration effect to relate food, place, history and culture of the nation that keeps and inherit them. Narration is a good way to strengthen touristic experience. Restaurants can focus on this strategy to attract tourists because places that are related with a specific history attract more visitors and tourists thus becoming an important element of marketing of destination.(Tellstrom et, al 2006)

Restaurants can be considered as service related more with the development of culinary tourism. Being this relationship, its promotion using different communication tools is very important. The most common tool of information transmission is the world of gossip. Another common tool for tourists is the discovery of restaurants while visiting a specific area. Also can be mentioned printed materials, brochures, newspapers, magazines or different restaurant web pages. Also television and internet bring different restaurants to the attention of people.

The tendency of tourists to eat traditional dishes can be increased but firstly negative views regarding this way of cooking has to be changed. An alternative are restaurants- living rooms where tourists feel more comfortable (Ab Karim \& Chi 2011). It is very important to offer a variety of traditional dishes not just the dishes that are known by tourists. At the same time there is a growing interest regarding production of specific specialties and creation of unique products that are typical for the area. This alternative brings a strong relationship between the sector of restaurants, environment and producers of area growing the level of authentic experiences for visitors and tourists of a place (Clarc \& Chabrell 2007)

Restaurants that offer qualitative products have an important contribution in the improvement of local food and the system of production relating to the quality of product and service. The importance of local food, as part of menus, can be understood and managed in different ways on restaurants.

There are a lot of factors that define the success and the failure of a destination for the development of culinary tourism. Among these factors restaurants have a role on the promotion of local food. (According to Everett\&Aitchison 2008) Restaurants are considered to be as the closest service related with culinary tourism and acts as a mediator between local producers and tourists, communicating with each of them being mindful for local situation. Despite of the important role that restaurants play in the development of culinary tourism, Hjalager and Richards (2002) present the argument that few restaurants have developed a comprehensive strategy focused on the evaluation of local food and the typical cuisine of destination. The reasons for this argument are different. In one direction can be argued that there are restrictions or barriers that don't let the managers to utilize totally local food as an attraction or a touristic source.

According to Smith and Xiao (2008) the most common restriction that cuisine chiefs and restaurant managers have in the use of local food is related with the difficulty of full accessibility in components and with the full safety of their quality. The determination of right relations with local stakeholders gives to restaurants the possibility of reduction of barriers that are in the use of local food as a touristic source in destination. The use of local food in restaurants and the placement of direct relationships with local community can affect in the improvement of local production and the image of destination and it also creates a full package of authentic experiences for tourists, impacting in the differentiation of destination and in the creation of a competitive advantage. 
The use of local food presents a good alternative also for restaurants in the placement of a competitive advantage in the sector where they are part of. This strategy affects positively in the creation of a special identity and in the strengthening of competitive positions in a business environment where is very important the process of continuous improvement to fulfill customer's demands that are in a continuous growth.

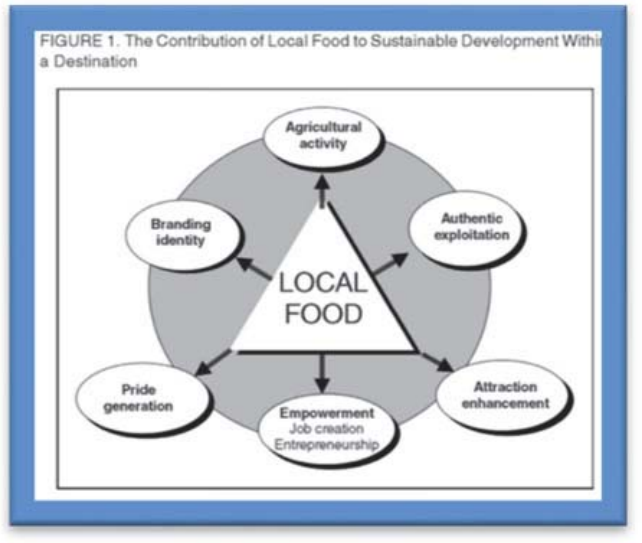

Source: Telfer D\& Wall G.,(1996) Linkages between tourism and food production

\section{Traditional Cuisine of the North of Albania}

Despite different influences, the gastronomy of this area is largely identified with the Mediterranean gastronomy. However, the local products of this area are known for their simplicity and clear territorial identity. The combination of coastal area, rivers, cross-border freshwater lake, plains, as well as mountains allow to enjoy the taste of simple and yet utterly delicious meals.

The mixture of high quality meat, especially veal and lamb; lake fish such as carp, eel, bleak and grey mullet; humble and yet fresh dairy products such as goat, cow and sheep cheese and yoghurt; delicious fruit and vegetables grown in this territory such as okra, aborigines, onions, tomatoes and figs, pomegranates, grapes and alike provide something for the traveler to look forward to discovering! We would like to describe to you the gastronomic similarities of the lakeshores different in their habits and religion, and to introduce you to the richness and variety of gastronomic pleasures identical only at first sight, and to prepare you for the complete opposites of common and known. We would like to introduce you to the uniqueness and rich diversity of an ethno-gastronomic route in the area of the Shkodra Lake which combines all of this at once and which small part we represent to you in this edition. Simply speaking, we want to convey the smell of the "tave krapi", smell of the marinated carp, to open up your appetite and yet slowly open the door of gastronomic pleasures that this area has to offer.

Corn is a widespread product in the north of Albania zone creating an important food basis not only for the production of bread but also for sweet or salty food. Climatic situation of the zone creates favorable conditions for the production and conservation of other products like: pasterma- a kind of dry meat, jufka- a variety of pastas, trahana- filled bowels that are used during the winter. The most used vegetables in cooking are beans, potatoes, cabbage, onion and garlic. The tradition of zone is also their drying in order to use them during the year.

During the last 10 years, the sector of restaurants has undergone a visible growth with touristic destinations that have doubled the number of restaurant units. In Albania there are a lot of restaurants that serve to a clientele consisting in foreign tourists. There are also restaurants that have local and national clientele. According to INSTAT publications, ventures that have a commercial activity in hotels and restaurants have given a high contribution in the economy in the last year. According to published data of INSTAT, ventures with commercial activity, hotels, cafés and restaurants have taken $59.6 \%$ of total registered. The index of "Hotels, cafés and restaurants" have recorded a growth of $0.1 \%$, a growth that has come as a result of the growth of the subgroup cafés-restaurants (INSTAT 2013)

\section{Research Methods}

For this research has been selected Shkodra city, a city in the North of Albania, as a possible gastronomic tourism 
destination. This region is indeed an interesting place to study local food and traditional cuisine as it has an enviable culinary tradition. Over the last few years the national government has been trying to leverage the local tradition on the art of food, to create a new tourism experience, to add this experience to the traditional touristic activities, in order to attract a new target of consumers also increasing the consumer satisfaction. This objective goes with the increasing number of tourists that their choice of a destination is affected by the culinary offer of the destination and to the statistics which reveal that $35 \%-40 \%$ of the total touristic expenditures go on food and drink.

Tourism in Shkodra region holds great potential in attracting tourists with a widespread system of authentic typical recourses, in which food and drink holds a special place.

\section{The Objectives of this Study}

1. To understand the role of local food in restaurants

2. To understand how much do local food affect tourists in the choice of a destination, according to managers and chefs restaurants

\section{Data Collection}

Research was carried out through a questionnaire delivered in 39 restaurants registered in Shkodra region.

The questionnaire was divided in two parts. The first part investigated the extent to which managers and chefs of restaurants assess the role of local food in their business. The second part of the questionnaire evaluates how much do local food affect tourists in the choice of a destination, according to managers and chefs restaurants. The survey was conducted during December 2013- January 2014.

\section{Results}

A lot of studies have confirmed that tourist's interest in and preferences for food in a destination can play a significant role in influencing their choice of a destination (Cohen \&Avieli, 2004; Hall \& Michell, 2001; Hall \& Sharples, 2003, Horng \& Tsai, 2012). Based on this fact, the first part of the research had the aim of understanding the role of local food in their restaurants.

Table 1: Presence of local food and drink in the menu

\begin{tabular}{ll}
\hline \multicolumn{2}{l}{ Presence of local food and drink in the menu Mean Standard deviation } \\
\hline 1 & Typical products 2.5711 .0894 \\
\hline 2 & Bio products 2.3551 .0818 \\
\hline 3 & Typical recipes 3.3571 .5495 \\
\hline
\end{tabular}

As shown in the table results, restaurants use typical products, bio products and typical recipes. They understand their relevance in customer satisfaction and customer loyalty, but they could do much more for this topic. Most of the restaurants select a limited number of traditional recipes instead of a numerous possible list of them. They use a brief list which does not represent the great heritage of Shkodra culinary offer. They also focus only in the most popular recipes instead of introducing the richness of ingredients and assortment of the area.

Table 2: Kind of cuisine served in the restaurant

\begin{tabular}{ll}
\hline Kind of cuisine served in the restaurant Mean Standard deviation \\
\hline 1 & Local 3.481 .236 \\
\hline 2 & Traditional 2.67 1.245 \\
3 & International 1.929 1.1411 \\
4 & Mixed 3.74 1.418 \\
\hline
\end{tabular}

Table two shows the extent to which restaurant managers and chefs reported using different kinds of cuisines, local, traditional, international respectively. According to the table result, it is evident that restaurants focus on the strategy of mixing the alternatives. This result shows that the market segment of the restaurants in study is diverse in their attitude toward food. 
Table 3: Relevance of traditional food

\begin{tabular}{l|c|c|c|c|c}
\hline Relevance of traditional food & Never & Almost never & $\begin{array}{c}\text { I don't give } \\
\text { importance to the fact }\end{array}$ & Almost always & Always \\
1. Use typical dishes & 1.99 & 6.75 & 5.81 & 27.10 & 58.35 \\
2. Use local products & 5.62 & 7.34 & 4.19 & 32.11 & 50.74 \\
3. Use seasonal products & 0.34 & 1.21 & 1.10 & 43.50 & 53.85 \\
\hline
\end{tabular}

\begin{tabular}{|l|c|c|c|c|c|}
\hline $\begin{array}{c}\text { Attitude toward the } \\
\text { use of local food }\end{array}$ & $\begin{array}{c}\text { I intend to } \\
\text { increase my } \\
\text { use }\end{array}$ & $\begin{array}{c}\text { I intend, but } \\
\text { not now }\end{array}$ & $\begin{array}{c}\text { I am not } \\
\text { interested in } \\
\text { changes }\end{array}$ & $\begin{array}{c}\text { I am not increasing my usage } \\
\text { because I have reached a } \\
\text { satisfactory level }\end{array}$ & $\begin{array}{c}\text { No, because I } \\
\text { do need not }\end{array}$ \\
\hline 1. Typical products & 47.83 & 42.07 & 1.22 & 6.43 & 2.45 \\
\hline 2. Typical recipes & 39.22 & 43.67 & 2.31 & 7.67 & 7.13 \\
\hline
\end{tabular}

Table three shows the relevance of the traditional food in the restaurant industry by analyzing the use of typical dishes, local products and seasonal products. As the results show it is evident that restaurant managers and chefs give great importance to the choice of their dishes and products, by using local product and seasonal products to fully accomplish the recipes of the typical dishes related to the land, culture and atmosphere of the place.

Results of table four also show that the influence of typical products and typical recipes is on a satisfactory level. Restaurant managers and chefs are re-evaluating the importance of using local food and the influence that local food has on the satisfaction of their customers.

The second part of the research evaluates how much do local food affect tourists in the choice of a destination, according to managers and chefs restaurants. Restaurants were asked to answer these questions:

1. How much do local products affect tourist's choice of a destination?

2. How much do local products fulfill the tourist's expectations?

Results from the in-depth interviews reveal positive influence in both cases. Both groups supported the fact that local food is a tourist attraction now and is a good tourist attraction. Food is a basic foundation that all visitors enjoy no matter their country of origin, religion, gender, age or any other differentiating criteria. Food has more potential than any other tourism experiences to create a long lasting impression. This because food involves all five human senses: sight, smell, taste, touch and sound. But still there are barriers for developing this kind of tourism, because of the lack of culinary knowledge, table manners or local culinary preferences.

An important aspect of evaluation regarding gastronomic products is the fact how they are linked to the territory of origin. A visitor's relationship with the physical environment can be stronger than in other tourism sectors. Tourists play greater value to products that they can associate with a specific region. The character of the region, the skills of the producers and the local community are perceived as containing more meaningful information about food. Some environmental factors such as geography and climate influence on the available agriculture products with an impact also in traditional recipes and the production process.

There is a widely perception that the purchase of local food helps the economy and the local environment. Additionally restaurant managers say that they are prepared to pay more attention to the quality of food they offer and especially to the traditional food they offer, by having in mind the territory of origin of the inputs, which need to be from the same destination and at the same time, the impact of the local community in enriching the gastronomic offer with traditional recipes.

\section{Conclusions}

This research has attempted to investigate the role of the typical dishes in the total experience and satisfaction of the tourists visiting the city of Shkodra, a region that has an established image as a gastronomy centre in the country. The idea of linking food and place is a powerful one and is a way of experiencing authenticity through food.

Research findings suggest that according to the restaurant managers and chef's local food can play a significant role in promoting their businesses and in creating a competitive advantage in their sector as well as influencing the tourist's decisions regarding dining experiences. Restaurant chefs and managers are willing to increase the use of typical dishes and recipes as a way to increase the percentage of tourists dining experiences. A crucial point of this activity is the relationship between restaurant managers and local producers. They offer is sometimes limited and they do not have always the possibility to fulfill restaurant needs. The study also revealed several barriers related to the information and 
promotional activities to better represent the destination. They also claimed that there are difficulties in promoting this kind of tourism which may be a consequence of the fragmented nature of the sector.

Our findings highlight the importance of the local authorities to create links between the stakeholders related with this subject. By creating these links, the value chain can improve the quality of the gastronomic products to present the gastronomic offer effectively to the market.

Another critical point of the value chain is the community and their admittance in participating in the value chain offer by retaining traditions and local resources. This would allow chefs in gathering information about a great variety of typical dishes and local tradition, ingredients and a better way to cook following local culture and local traditions.

Food has a great potential in enhancing visitors experiences and to contribute in creating a local brand that can differentiate the city in study.

Our findings help to investigate in a neglected area of tourism research.

\section{References}

Boniface, P., 2003. Tasting tourism: Traveling for food and drink. Burlington: Ashgate Publishing.

Hall, M. and R. Mitchell, 2000. We are what we eat: Food, tourism and globalization. Tourism, Culture Project. and Communication, 2(1): 29-37.

Hall, C. M., \& Mitchell, R. (2006). Gastronomic tourism: Comparing food and wine tourism experiences. In M. Novelli (Ed.), Niche tourism: Contemporary issues, trends and cases (pp. 73-88.). Oxford: Elsevier Butterworth-Heinemann.

Ab Karim, S. and C.G Chi (2011)"Culinary tourism as a destination attraction: An empirical examination of destinations' food image" Journal of Hospitality Marketing and Management (531-555)

Clark, G., \& Chabrel, M. (2007). Measuring integrated rural tourism. Tourism Geographies, 9, 371-386.

Fox R. (2007) Reinventing the gastronomic identity of Croatian tourist destinations. International Journal of Hospitality Management, 26, 546-559

Chang et al., 2011 Atributes that influence the evaluation of travel dining experience. When east meet west. Tourism Management, 32(2), 307-316

Chang, Kivela \& Mak 2011. Food preferences of Chinese tourists. Annals of tourism research, 37(4), 989-1011

Erich Wolf 2014. Have fork will travel: A Practical Handbook for Food \& Drink Tourism Professionals

Kennedy et al., 2004. Globalization of food systems in developing countries: a synthesis of country case studies. Food and nutrition paper no 83 pp1-26. Rome: food and agriculture organization of the United Nations

Hall, C. M., \& Sharples, L. 2008. Food events, festivals and farmers' markets: An introduction, food and wine festivals and events around the world: Development, management and markets (pp.3-22). Oxford: Butterworth Heinemann

Michael Symons 1999 Gastronomic authentic and sense of the place.

Sheldon, P.J. and M. Fox, 1988. The role of foodservice in vacation choice and experience: A Perceived Risk and International Tourism. Annals of cross-cultural analysis. J. Travel Res., 27(2): 9-15.

Gunn, C., 1979. Tourism planning. New York: Crane. Tourism Russak and Company, Inc.

Practical Farmers of lowa: Grocery and Hotel, Restaurant and Institutional Study, Scanlan and Associates, Huber, G and Karp, R 2000

Gibson, E 1995. Selling to restaurants. In Direct Farm Marketing and Tourism Handbook, University of Arizona College of Agriculture, Cooperative Extension,

Tellstrom, R 2006. Consuming heritage, the use of local food culture in branding Place branding 2(2)

Everett, S \& Aitchison, C 2008 The role of food tourism in sustaining the regional identity: A case study of Cornwall, South West England. Journal of sustainable tourism 16(2), 150-167

Greg Richards (2002) Tourism and gastronomy

Smith, S \& Xiao, H (2008) Culinary tourism supply chains: A preliminary examination. Journal of travel research, 46(3), 289-299

Hall, C. M., Sharples, L., Mitchell, R., Macionis, N., \& Cambourne, B. (Eds.). (2003). Food tourism around the world: Development, management and markets. Oxford: Butterworth Heinemann.

Hewitt, B. (2009). The town that food saved: How one community found vitality in local food. Emmaus, PA: Rodale. 